\title{
Identification of subjects with occupational exposure to asbestos, quartz, and welding fumes in the general population of Telemark, Norway
}

\author{
Halfrid P. Waage, $\mathrm{MD}^{1}$ and Bjørn Hilt, $\mathrm{MD}^{1,2}$ \\ ${ }^{I}$ Telemark Central Hospital, Department of Occupational and Environmental Medicine, Skien, Norway \\ ${ }^{2}$ Current address: University Hospital of Trondheim, Department of Occupational Medicine, Trondheim, Norway
}

Corresponding author: Halfrid P. Waage, Telemark Central Hospital, Department of Occupational and Environmental Medicine, N-3710 Skien, Norway Phone: +47-35 583000 Fax: +47-35 583105 E-mail: halfrid.waage@tss.telemax.no

\begin{abstract}
A questionnaire survey on the lifetime exposure to asbestos, quartz, and welding fumes among males aged 38-48 years $(n=9,186)$ and females aged $40-43$ years $(n=3,495)$ in the county of Telemark, Norway was carried out in 1989-90. The overall response rate was $72 \%$. A total of $42.9 \%$ of the males and $39.8 \%$ of the females were current smokers. Among the male responders, $32.5 \%, 16.4 \%, 21.1 \%$, and $10.5 \%$ had been exposed at any time to asbestos, quartz, welding fumes, and stainless steel welding fumes respectively. The figures for exposure among female responders were negligible, i.e. $0.7 \%, 0.5 \%, 0.5 \%$, and $0.1 \%$ respectively. The mean reported duration of exposure for the exposed subjects was 9.8 years for asbestos, 8.8 years for quartz, and 11.3 years for welding fumes. Subjects reporting any one of the exposure factors were more likely to be smokers. Exposure at the time of the survey was reported by $13.8 \%$ among the asbestos-exposed subjects, and by $22.7 \%$ and $34.4 \%$ among those exposed to quartz and welding fumes respectively. The need for primary intervention is emphasized. Smoking intervention in those already exposed to any of these determinants for lung cancer is also needed, as tobacco smoke may increase the lung cancer risk further.
\end{abstract}

Key words: smoking, gender, combined exposures, population survey, prevalent exposure

\section{INTRODUCTION}

Although tobacco smoking is the main single cause of lung cancer, it has been estimated that $15-20 \%$ of all lung cancers occurring in men in industrialized societies are related to exposures at work (1). However, such an estimate depends on the distribution of the exposures of concern and cannot necessarily be generalized to a particular population (2). Moreover, such a proportion may also vary with gender, social class, and other occupational exposures in the population. Therefore, the key point in estimating the impact of occupational exposures is to survey the exposures of interest in that particular population. Population-based surveys may serve as a basis for the identification of subjects at risk of lung cancer i) for primary and secondary intervention; and ii) in the event that there is a breakthrough in diagnostic techniques or in therapy. In relation to occupational lung cancer, exposure to asbestos (3), quartz $(4,5)$, and welding fumes, in particular from stainless steel $(6,7)$, is of major concern. In 1982-83, asbestos exposure was surveyed in the male population older than 40 years of age in the county of Telemark, Norway (8). That survey of $21,483 \mathrm{men}$ is one of the few studies on asbestos exposure in the general population. The present study was conducted to further extend and complement that survey. Thus, males aged 38-48 years and females aged $40-43$ years were targeted in 1989-90 with the intention of identification and quantification of subjects at increased risk for lung cancer as a result of being exposed to asbestos, quartz or welding fumes.

\section{SUBJECTS AND METHOD}

Telemark is one of 19 counties in Norway, and has 118,618 inhabitants. The county is rather industrialized with $26 \%$ of the population occupied in manufacturing and $7 \%$ in construction. The corresponding national figures are $18 \%$ and $7 \%$ (9). The industrial activities in Telemark consist of electrochemical industries, shipyards, various workshops, and stone quarries.

The present study was conducted in collaboration with the National Health Screening Service of Norway in 1989-90. All males $(\mathrm{n}=3,681)$, and females $(n=3,495)$, born from January 1947 to 1949 in the 
county of Telemark were invited to a brief health status checkup ("40-åringsundersøkelsen"). In addition, all males born from January 1942 to 1946 and from January 1950 to 1951 in five of the urban municipalities in the county $(\mathrm{n}=5,505)$ were called for a chest radiograph screening examination. Thus, our study base comprised 12,681 subjects, i.e. 9,186 males aged 38-48 years (born 1942-51) and 3,495 females aged 40-43 years (born 1947-49).

All participants were asked to fill in a selfadministered questionnaire, which comprised a brief introduction on the significance of surveying workrelated exposure factors. The wording of the questions was: 1) "Have you ever been exposed to asbestos dust in your work?" If so; 2 ) "In what kind of industry or in which occupation did the exposure take place?" 3) "During which time periods did the exposure take place?" 4) "Would you consider the frequency of the exposure situations as "daily/almost daily", "1-2 times weekly", "1-2 times monthly", or "less frequent"?". Exposure in up to three workplaces could be specified for questions 2-4. The questions on exposure to quartz and welding fumes were identically designed. In addition it was specifically asked: "Have you ever been welding on stainless steel?", and "Would you consider the proportion of the welding time that was used for stainless steel welding as "full time", "more than $3 / 4$ of the time", "between $3 / 4$ and $1 / 2$ of the time", "between $1 / 2$ and $1 / 4$ of the time", or "less than $1 / 4$ of the time"?". Smoking status and the year of quitting, for ex-smokers, were also included.

The data were computed and analysed by using BMDP 386, modules 1D (simple data description), 2D (detailed data description), and 4F (analysis of twoway tables) (10).

\section{RESULTS}

After one postal reminder, 2,626 of the females (75\%) and 6,499 of the males $(71 \%)$ had answered the questionnaire, resulting in an overall response rate of $72 \%$. The response rate varied from $66 \%$ to $83 \%$ between municipalities.

A total of 2,919 (44.9\%) male responders and 38 $(1.5 \%)$ female responders reported exposure to any of the occupational risk factors. Table I shows that asbestos exposure was reported by $2,109(32.5 \%)$ of the males, while $1,067(16.4 \%)$ had been exposed to quartz, $1,369(21.1 \%)$ to welding fumes, and 681 $(10.5 \%)$ to stainless steel welding fumes. A total of 256 males (3.9\%) had reported exposure to asbestos, quartz, and welding fumes, while $1,100(16.9 \%)$ had been exposed to two of the risk factors (data not shown). The highest proportions of asbestos-exposed males were found in the industrialized municipalities, while the highest proportions of males who reported exposure to quartz or welding fumes were found in rural municipalities. Among females, asbestos exposure was reported by 18 subjects, while 14 persons had been exposed to quartz, 12 to welding fumes, and 3 to stainless steel welding fumes (Table I). Multiple exposures were reported by 3 females.

As presented in Table I, $42.9 \%$ of male responders reported current smoking while $28.5 \%$ were exsmokers. Consistently, increased proportions of both current and ex-smokers were found in those with exposure to any of the occupational factors. Among females, $39.8 \%$ were current smokers, and $19.9 \%$ exsmokers. The small number of exposed females precludes any conclusion on the relationship between exposure and smoking habits.

Table I. The number of exposed subjects and the distribution of smoking habits among them. Smoking habits in all 6,499 males and 2,626 females who responded to the questionnaire survey are given in the last column.

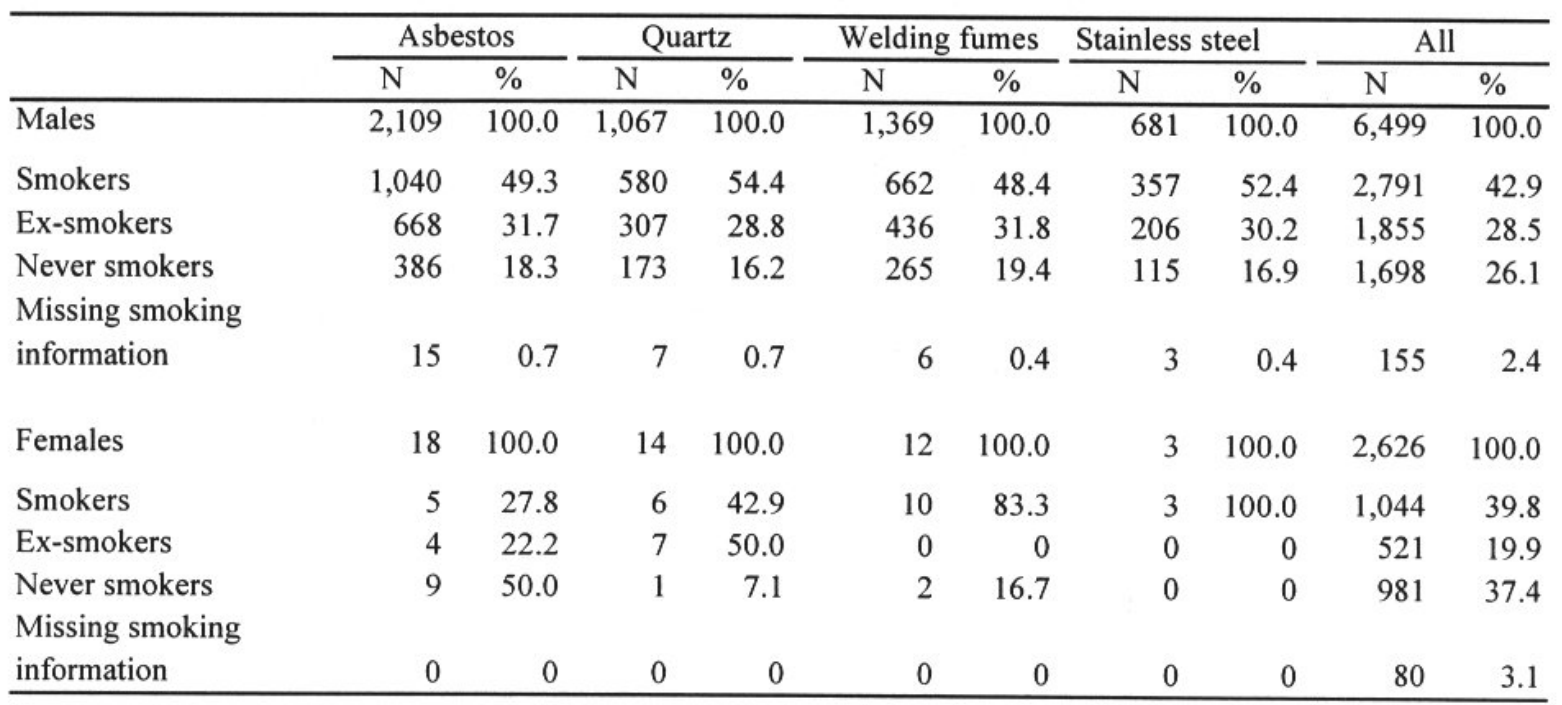


Table II presents the workplaces or occupations where the reported exposure to asbestos had occurred. Electrochemical and chemical industries were the most frequent sources of exposure $(24.0 \%)$. As is shown in Table III, road and railroad construction work constituted the major single source of quartz exposure $(22.8 \%)$. Also, $13.3 \%$ had reported quartz exposure in the ferroalloy industry. For welding fumes (Table IV), "machine shops, welding shops, offshore industries" and "maintenance workers in industry" were the major sources of exposure (18.3\% and $19.6 \%$ respectively).

Exposure was reported through 1990 for all of the agents. Among the asbestos-exposed subjects, 13.8\% stated ongoing exposure. This was most pronounced in "automobile repair shops" (Table II). Among those exposed to quartz or welding fumes, $22.7 \%$ and $34.4 \%$ respectively reported ongoing exposure. Current exposure to quartz dust was most frequently reported in relation to "agriculture", "unspecified industrial work", and "transport work" (Table III), while current exposure to welding fumes occurred most frequently in "building and construction work, agriculture" and in "road and railroad construction work" (Table IV).

The mean total length of multiple exposure periods was 9.8 years for asbestos, 8.8 years for quartz, and 11.3 years for welding fumes. It turned out that the greatest proportion of subjects had a cumulative exposure from one to ten years to each of the factors. For quartz and welding fumes "daily/almost daily exposure" was most commonly reported, while less frequent exposure was most common for asbestosexposed persons (Figure 1). Among the 681 individuals who reported stainless steel welding, 460 subjects had stated "exposure less than one fourth of the welding time".

\section{DISCUSSION}

In this relatively young part of the general population in the county of Telemark, substantial proportions of males reported exposure to asbestos, quartz, and welding fumes. This probably leaves these men at an increased risk for occupational lung diseases. The exposure revealed among women was negligible. Compared to the $42.9 \%$ of smokers in the whole group of males, increased proportions of smokers were observed among those exposed to any of the agents. In relation to lung cancer risk, smoking is known to act synergistically with asbestos (3), and at least exert an additive effect on the risk resulting from exposure to quartz (4). Thus, the smoking habits further aggravates the revealed exposure, at least to asbestos and quartz.

Table II. The workplaces/occupations where 2,127 males and females reported to have experienced asbestos exposure in the questionnaire survey.

\begin{tabular}{|c|c|c|c|c|}
\hline \multirow{2}{*}{$\begin{array}{l}\text { Workplace/occupation } \\
\text { Electrochemical and chemical industries }\end{array}$} & \multicolumn{2}{|c|}{$\begin{array}{l}\text { Number of reported } \\
\text { workplaces }(\%) *\end{array}$} & \multicolumn{2}{|c|}{$\begin{array}{c}\text { Proportion of workplaces with } \\
\text { exposure at the time of the } \\
\text { survey }(\%) \dagger\end{array}$} \\
\hline & 710 & $(24.0)$ & $72 / 660$ & $(10.9)$ \\
\hline Building and construction industries & 294 & $(9.9)$ & $25 / 274$ & $(9.1)$ \\
\hline Shipyards & 137 & $(4.6)$ & $4 / 133$ & $(3.0)$ \\
\hline Seaman in engine room & 346 & (11.7) & $6 / 337$ & $(1.8)$ \\
\hline Other seamen & 114 & $(3.8)$ & $2 / 106$ & (1.9) \\
\hline Ferroalloy industries/iron foundries & 189 & $(6.4)$ & $6 / 179$ & (3.4) \\
\hline Automobile repair shops & 288 & $(9.7)$ & $55 / 282$ & $(19.5)$ \\
\hline Electrical equipment industries & 41 & (1.4) & $0 / 41$ & $(0.0)$ \\
\hline Cement industries (not asbestos) & 23 & $(0.8)$ & $2 / 22$ & $(9.1)$ \\
\hline Paper and paper pulp workers & 29 & $(1.0)$ & $1 / 25$ & $(4.0)$ \\
\hline Mechanics/metal workers (including welders) & 194 & $(6.5)$ & $14 / 184$ & $(7.6)$ \\
\hline Refractory material industries & 15 & $(0.5)$ & $1 / 15$ & $(6.7)$ \\
\hline Wood working industries & 180 & $(6.1)$ & $20 / 167$ & $(12.0)$ \\
\hline Insulators & 34 & $(1.1)$ & $1 / 32$ & (3.1) \\
\hline Agriculture and fishing & 18 & $(0.6)$ & $0 / 16$ & $(0.0)$ \\
\hline Sale and storeroom & 21 & $(0.7)$ & $3 / 21$ & $(14.3)$ \\
\hline Other occupations & 330 & $(11.1)$ & $53 / 301$ & $(17.6)$ \\
\hline
\end{tabular}

* 74 subjects had not given detailed information on the place of exposure, while 426 persons reported two places of exposure and 242 persons reported yet a third place, resulting in a total of 2,963 reported workplaces/occupations.

$\uparrow$ Some subjects had not reported the duration of exposure. Hence, the denominator may be smaller than the number of reported workplaces. 
Table III. The workplaces/occupations where 1,081 males and females reported to have experienced quartz exposure in the questionnaire survey.

\begin{tabular}{|c|c|c|c|c|}
\hline \multirow{2}{*}{$\frac{\text { Workplace/occupation }}{\text { Tunneling, mining, stone quarry }}$} & \multicolumn{2}{|c|}{$\begin{array}{c}\text { Number of reported } \\
\text { workplaces }(\%) *\end{array}$} & \multicolumn{2}{|c|}{$\begin{array}{c}\text { Proportion of workplaces } \\
\text { with exposure at the time of } \\
\text { the survey }(\%) \dagger\end{array}$} \\
\hline & 163 & $(12.7)$ & $18 / 141$ & $(12.8)$ \\
\hline Road and railroad construction work & 291 & $(22.8)$ & $56 / 254$ & $(22.0)$ \\
\hline Foundries & 60 & (4.7) & $1 / 56$ & (1.8) \\
\hline Sandblasting & 26 & (2.0) & $1 / 24$ & $(4.2)$ \\
\hline Building and construction work & 146 & (11.4) & $31 / 138$ & $(22.5)$ \\
\hline Transport work & 67 & $(5.2)$ & $14 / 57$ & $(24.6)$ \\
\hline Ferroalloy industries & 170 & (13.3) & $12 / 159$ & $(7.5)$ \\
\hline Unspecified industrial work & 220 & $(17.2)$ & $50 / 200$ & $(25.0)$ \\
\hline Porcelain work & 53 & $(4.1)$ & $8 / 46$ & $(17.4)$ \\
\hline Agriculture & 6 & $(0.5)$ & $2 / 3$ & $(66.7)$ \\
\hline Other occupations & 77 & $(6.0)$ & $15 / 60$ & $(25.0)$ \\
\hline
\end{tabular}

* 36 subjects gave no information on the source of exposure, while 120 persons reported two places and 57 persons reported yet a third place, resulting in a total of 1,279 reported workplaces/occupations.

$\uparrow$ Some subjects had not reported the duration of exposure. Hence, the denominator may be smaller than the number of reported workplaces.

Table IV. The workplaces/occupations where 1,381 males and females reported to have experienced exposure to welding fumes in the questionnaire survey.

\begin{tabular}{lrrrr}
\hline & \multicolumn{2}{c}{$\begin{array}{c}\text { Proportion of workplaces } \\
\text { Wumber of reported } \\
\text { workplaces (\%) }\end{array}$} & $\begin{array}{c}\text { with exposure at the time of } \\
\text { the survey }(\%) \dagger\end{array}$ \\
\hline Machine shops, welding shops, offshore industries & 395 & $(18.3)$ & $78 / 371$ & $(21.0)$ \\
Shipyards & 336 & $(15.5)$ & $19 / 329$ & $(5.8)$ \\
Road and railroad construction work & 41 & $(1.9)$ & $15 / 41$ & $(36.6)$ \\
Building and construction work, agriculture & 75 & $(3.5)$ & $45 / 62$ & $(72.6)$ \\
Other maintenance workers and mechanics & 204 & $(9.4)$ & $29 / 180$ & $(16.1)$ \\
Automobile repair shops & 161 & $(7.4)$ & $38 / 155$ & $(24.5)$ \\
Maintenance workers in industry & 423 & $(19.6)$ & $92 / 402$ & $(22.9)$ \\
Metal and sheet metal workers & 227 & $(10.7)$ & $43 / 216$ & $(19.9)$ \\
Electrical equipment industries, electricians & 47 & $(2.2)$ & $9 / 42$ & $(21.4)$ \\
Other occupations & 253 & $(11.7)$ & $76 / 221$ & $(34.4)$ \\
\hline
\end{tabular}

* 30 subjects had given no further information, while 313 persons reported two places of exposure and 249 persons reported yet a third place, resulting in a total of 2,162 reported workplaces/occupations.

$\dagger$ Some subjects had not reported the duration of exposure. Hence, the denominator may be smaller than the number of reported workplaces.

The results showed that asbestos exposure has occurred in a variety of occupations and workplaces (Table II). This follows from the widespread use of asbestos. The proportions of current exposure to asbestos, quartz, and welding fumes were surprisingly high appreciating the improvement in industrial hygiene that has occurred during the last decades in the Norwegian society. In particular, it was surprising that $13.8 \%$ of those who had reported asbestos exposure, stated that they were currently exposed at their workplace, knowing that the use of asbestos has been regulated by legislation since 1977 .

In the present study, $28 \%$ of the recruitment population did not answer the questionnaire. Others have found that nonresponders have quite similar exposure to responders $(11,12)$. A higher response rate would 


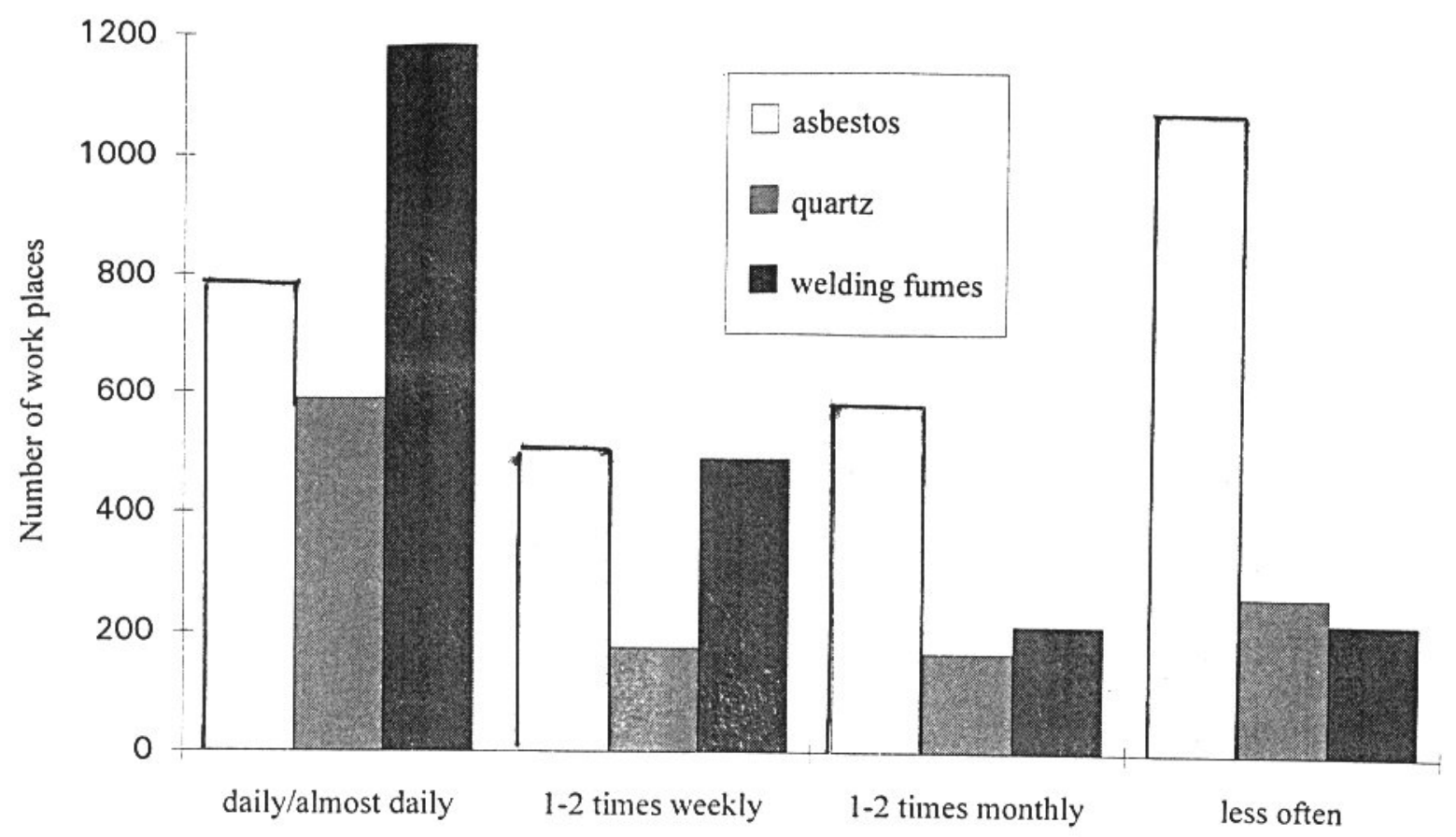

Figure 1. The "frequency of exposure" to asbestos, quartz, and welding fumes according to questionnaire information.

therefore not necessarily have influenced the results substantially. However, some caution should be taken in generalisation of the estimates. Males born 1942-46 and 1950-51 were surveyed only in five urban municipalities, while males and females born 1947-49 were surveyed in the whole county. Thus, a bias may have been introduced because exposure to asbestos proved to be highest in the urban municipalities.

A study in the western part of Norway revealed lifetime prevalences of exposure to asbestos, quartz, and welding fumes among males aged 35 to 54 years of $37 \%, 18 \%$, and $27 \%$ respectively (13), which is in accordance with the present results. On the other hand, in the previous study in the county of Telemark, $18 \%$ of males born before 1942 had been asbestos-exposed as recorded by an almost identically worded questionnaire as in the present study (8). Upon validation of the questionnaire in that study it turned out that the question: "Have you ever been exposed to asbestos?" had a specificity of $97.3 \%$ and a sensitivity of $44.6 \%$. It is possible that an increased consciousness on workrelated exposures during the last years has improved the sensitivity and thus has contributed to the higher proportion of reported exposure in the present study. The reported duration and frequency of exposure in the present study indicates that the exposure to the surveyed agents has been quite significant.

Based on the present study and the previous study from 1982-83 (8), about 30,600 subjects in the county of Telemark have been surveyed with respect to asbestos exposure and smoking habits. These subjects constitute about $43 \%$ of the males and $4 \%$ of the females older than 15 years in the county (14). Correspondingly, $10 \%$ of males and $4 \%$ of females have been surveyed on exposure to quartz and welding fumes. The knowledge on exposure to asbestos, quartz, and stainless steel welding fumes in the population in the county of Telemark can be used to prevent workrelated lung cancer. Primary intervention to reduce the exposure should target workplaces/occupations where current exposure is known to occur (Table II-IV). Because of the long latency, previous exposure to lung carcinogens is a latent source of lung cancer in the population that will continuously result in new cases during the forthcoming decades. Secondary intervention by means of anti-smoking advice may reduce the risk of disease in previously exposed subjects. The greatest effect can be expected among asbestosexposed subjects because of the synergistic effect from smoking.

\section{ACKNOWLEDGEMENTS}

This study was funded by the Norwegian Research Council for Science and Humanities and by Telemark County Council. The authors thank the National Health Screening Service of Norway for the co-operation in the distribution of questionnaires. We thank Dr Lars Vatten for comprehensive advice during preparation of the manuscript. We also acknowledge Dr Sverre Langård for his advice in an earlier phase of the work. We are grateful to Ms Liv Brun for punching of data and to Ms Patricia Flor for linguistic assistance. 


\section{REFERENCES}

1. Vineis P, Simonato L. Proportion of lung and bladder cancers in males resulting from occupation: a systematic approach. Arch Environ Health 1991; 46: 6-15.

2. Boffetta P, Kogevinas M, Simonato L, Wilbourn J, Saracci R. Current perspectives on occupational cancer risks. Int J Occup Environ Health 1995; 1: 315-25.

3. Hammond EC, Selikoff IJ, Seidman H. Asbestos exposure, cigarette smoking and death rates. Ann NY Acad Sci 1979; 330: 473-90.

4. Pairon JC, Brochard P, Jaurand MC, Bignon J. Silica and lung cancer: a controversial issue. Eur Respir J 1991; 4: 730-44.

5. Amandus HE, Shy C, Castellan RM, Blair A, Heineman EF. Silicosis and lung cancer among workers in North Carolina dusty trades. Scand J Work Environ Health 1995; 21 (suppl 2): 81-3.

6. Simonato L, Fletcher AC, Andersen A, et al. A historical prospective study of European stainless steel, mild steel, and shipyard welders. Br J Ind Med 1991; 48: 145-54.

7. Lauritsen JM, Hansen KS. Lung cancer mortality in stainless steel and mild steel welders: a nested casereferent study. Am J Ind Med 1996; 30: 383-91.

8. Hilt B, Langård S, Lund-Larsen PG, Lien JT. Previous asbestos exposure and smoking habits in the county of Telemark, Norway - a cross-sectional population study. Scand J Work Environ Health 1986; 12: 561-6.

9. Central Bureau of Statistics of Norway. "Labour market statistics 1990." Oslo: Statistisk sentralbyrå, 1990.

10. Dixon JW. "BMDP statistical software manual." Berkeley: University of California Press, 1990.

11. Bakke P, Gulsvik A, Lilleng P, Overå O, Hanoa R, Eide GE. Postal survey on airborne occupational exposure and respiratory disorders in Norway: causes and consequences of non-response. $J$ Epidemiol Community Health 1990; 44: 316-20.

12. Selikoff IJ , Seidman H. Evaluation of selection bias in a cross-sectional survey. Am J Ind Med 1991; 20: 615-27.

13. Bakke P, Baste V, Hanoa R, Gulsvik A. Occupational airborne exposure of the general population of a Norwegian county. Scand J Work Environ Health 1992; 18: 44-51.

14. Central Bureau of Statistics of Norway. "Population statistics 1990, volume III, survey." Oslo: Statistisk sentralbyrå, 1990. 